\title{
Investigation of Gamma-aminobutyric acid (GABA) A receptors genes and migraine susceptibility
}

Francesca Fernandez ${ }^{1}$, Teresa Esposito ${ }^{2}$, Rod A Lea ${ }^{1,3}$, Natalie J Colson ${ }^{1}$, Alfredo Ciccodicola ${ }^{2}$, Fernando Gianfrancesco ${ }^{2}$ and Lyn R Griffiths*1

\author{
Address: ${ }^{1}$ Genomics Research Centre, Griffith Institute for Health and Medical Research, Griffith University, Gold Coast, Queensland, Australia, \\ 2Institute of Genetics and Biophysics, Adriano Buzzati-Traverso, CNR, Naples, Italy and ${ }^{3}$ Institute of Environmental Science and Research, \\ Wellington, New Zealand \\ Email: Francesca Fernandez - f.fernandez@griffith.edu.au; Teresa Esposito - espositot@igb.cnr.it; Rod A Lea - Rod.Lea@esr.cri.nz; \\ Natalie J Colson - n.colson@griffith.edu.au; Alfredo Ciccodicola - ciccodic@igb.cnr.it; Fernando Gianfrancesco - gianfrancesco@igb.cnr.it; \\ Lyn R Griffiths* - l.griffiths@griffith.edu.au \\ * Corresponding author
}

Published: 16 December 2008

BMC Medical Genetics 2008, 9:109 doi:10.1186/147/-2350-9-109
Received: 22 March 2008

Accepted: 16 December 2008

This article is available from: http://www.biomedcentral.com/I47I-2350/9/109

(C) 2008 Fernandez et al; licensee BioMed Central Ltd.

This is an Open Access article distributed under the terms of the Creative Commons Attribution License (http://creativecommons.org/licenses/by/2.0), which permits unrestricted use, distribution, and reproduction in any medium, provided the original work is properly cited.

\begin{abstract}
Background: Migraine is a neurological disorder characterized by recurrent attacks of severe headache, affecting around $12 \%$ of Caucasian populations. It is well known that migraine has a strong genetic component, although the number and type of genes involved is still unclear. Prior linkage studies have reported mapping of a migraine gene to chromosome $\mathrm{Xq}$ 24-28, a region containing a cluster of genes for GABA A receptors (GABRE, GABRA3, GABRQ), which are potential candidate genes for migraine. The GABA neurotransmitter has been implicated in migraine pathophysiology previously; however its exact role has not yet been established, although GABA receptors agonists have been the target of therapeutic developments. The aim of the present research is to investigate the role of the potential candidate genes reported on chromosome Xq 24-28 region in migraine susceptibility. In this study, we have focused on the subunit GABA A receptors type $\varepsilon$ (GABRE) and type $\theta$ (GABRQ) genes and their involvement in migraine.
\end{abstract}

Methods: We have performed an association analysis in a large population of case-controls (275 unrelated Caucasian migraineurs versus 275 controls) examining a set of 3 single nucleotide polymorphisms (SNPs) in the coding region (exons 3, 5 and 9) of the GABRE gene and also the 1478F coding variant of the GABRQ gene.

Results: Our study did not show any association between the examined SNPs in our test population $(P>0.05)$.

Conclusion: Although these particular GABA receptor genes did not show positive association, further studies are necessary to consider the role of other GABA receptor genes in migraine susceptibility. 


\section{Background}

Migraine is a common neurological disorder with variable expression, affecting more than $12 \%$ of the general population [1]. The exact cause is unknown and there are no recognizable diagnostic pathological changes. Migraine is a neurological disorder, characterised by recurrent headache that is associated with nausea and/or vomiting, photophobia and phonophobia. The International Headache Society (IHS) has formally classified migraine into two main subtypes: migraine with aura (MA) and migraine without aura (MO) [2]. These two subtypes have substantial symptomatic overlap, but MA sufferers experience distinguishing neurological disturbances (the aura) that usually precede the headache phase of an attack.

The pathogenesis and pathophysiology of migraine are poorly understood. A diverse group of variables have been implicated in the pathophysiology of migraine, in particular, the serotoninergic system, with drugs that release serotonin shown to precipitate migraine attacks [3], while drugs that interact with serotonin receptors have beneficial prophylactic and abortive effects [4]. Glutamate, which is a major excitatory neurotransmitter in the central nervous system, has also been broadly involved in migraine pathophysiology. Altered glutamate levels have been measured in migraine patients [5] and glutamate has been implicated in trigeminal activation and cortical spreading depression (CSD), [5]. In fact, stimulation of the trigeminovascular system may be responsible for the pain process during a migraine episode, whereas CSD seems to underlie the aura symptoms [6]. More specifically, CSD activates the afferences from the trigeminal system, which provokes an inflammation of meninges underlying the pain and causing the headache [7]. Another neurotransmitter that plays an important role in migraine pathophysiology, Gamma-aminobutyric acid (GABA) [8]. GABA, which acts mainly via GABA A and B receptors, is the main inhibitory neurotransmitter in the brain. Catecholaminergic, serotoninergic and glutamatergic neurons are all under GABAergic inhibitory control. GABAergic anticonvulsivant medications, are a first line of therapy for prevention for migraine [9]. Baclofen, a GABA $\mathrm{B}$ analog, has also been shown to have an antinociceptive effect in the central nervous system, and thus to be efficient in the prophylaxis of migraine [10]. Furthermore, GABA A receptor agonists (Sodium valproate, gabapentin, topiramate) are currently employed in preventing migraine or reducing the frequency and the duration of attacks $[11,12]$.

The GABA A receptor is a member of a superfamily consisting of pentamers of homologous subunits arranged around a central ion conducting channel (Cl- ions) [13]. There are 19 different subunit genes, divided into eight subunit classes: $\beta 1-3, \theta, \eta 1-2, \delta, \pi, \alpha 1-6, \gamma 1-3, \varepsilon$. GABA
A receptors are the targets of sedating drugs, such as benzodiazepines, barbiturates, neurosteroids, and ethanol [14].

While the mode of transmission of migraine is broadly believed to be multifactorial, a role for a major susceptibility gene has been postulated. In fact, migraine shows strong familial aggregation. Approximately 50\% of migraine sufferers have an affected first degree relative, with familial incidence figures varying from $61 \%$ to $90 \%$ [15]. Two Danish population based survey have provided evidence to suggest that MA and MO may be two distinct disorders with an independent genetic identity $[16,17]$. However, results of Australian [18] and Dutch [19] studies have suggested that migraine with and without aura are not etiologically distinct. It is most likely that there is at least some shared genetic liability between the two subtypes. Genetic characterization of the migrainous disorder is making steady progress with an increasing number of genomic susceptibility loci now identified on chromosomes 1q, 4q, 5q, 6p, 11q, 14q, 15q, 17p, 18q, 19p and $\mathrm{Xq}$ and more specifically in the Xq 24-28 region [20,21]. This region contains a cluster of GABA A receptor subunit (epsilon, alpha 3, theta) genes. A cluster of genes, GABREGABRA3-GABRQ, spans a genomic region of about 700 $\mathrm{Mb}$ (figure 1); GABRE and GABRA3 genes encode for epsilon and alpha3 subunits respectively and are transcribed in centromeric direction, whilst the GABRQ gene encodes for the theta subunit and is transcribed in telomeric direction. Interestingly, studies performed in rat demonstrate that these three subunits are co-expressed in specific brain regions, in particular the locus caeruleus, with studies demonstrating this may be involved in the migraine disorder [22].

In the present study, we investigated three Single Nucleotide Polymorphisms (SNPs), previously described (rs 2050843 and rs 22566882 in GABRE gene and rs 3810651 in GABRQ) and a new mutation in exon 9 of the GABRE gene, which has been recently identified by sequencing. These polymorphism studies were undertaken in a large Australian population of unrelated subjects involving 275 migraineurs and 275 matched controls.

\section{Methods \\ Subjects}

A cross-sectional association approach was employed, utilizing genomic DNA samples obtained from 275 migraine affected individuals and 275 controls. The populations consisted of Caucasians from the general Australian Community. Before commencing the study, ethical clearance was sought and approved by Griffith University's Ethics Committee for Experimentation on Humans. Individuals for the study were recruited from the local general popu- 


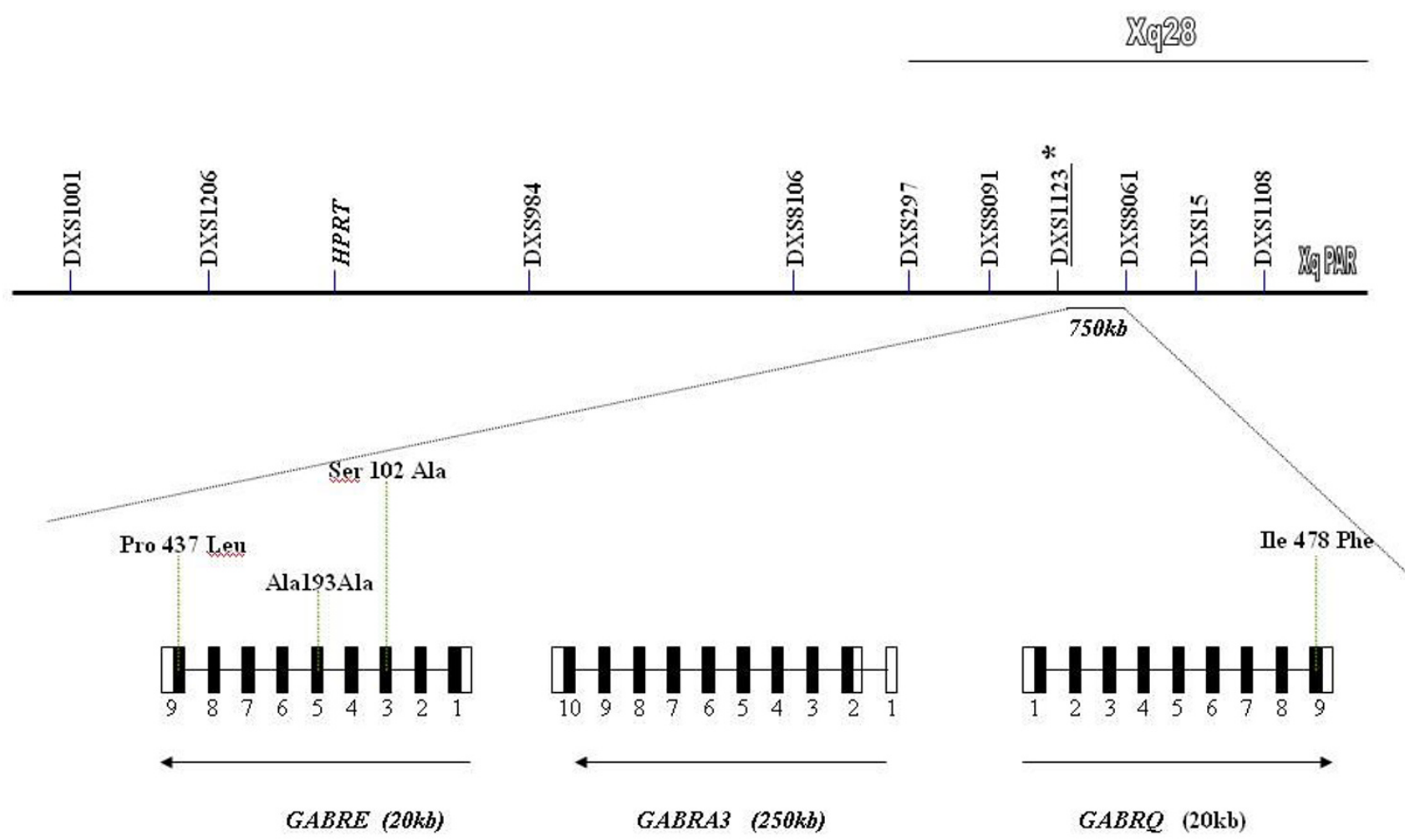

Figure I

Schematization of the location of the 4 studied SNPs on the chromosome X (q28). Pro 437 Leu is a new variation identified by sequencing of exon 9 of GABRE gene.

lation using advertising via notices at Doctors Surgeries and in Pharmacies, as well as through media release on local radio, television and in press articles. Potential participants contacted the Genomics Research Centre and suitability for inclusion in the study was determined using a detailed questionnaire completed by all participants, providing demographic parameters, ancestry information and family medical history. The control group consisted of individuals with no family history of migraine. Volunteers who did not meet these criteria were not included in the study. All recruited individuals for the study gave informed consent and were adult ( 18 years or older) Caucasians of European descent living in Australia, having emigrating ancestors within the last 160 years from various locations within the British Isles and other parts of Europe. In total 600 cases and an equivalent number of controls were collected over several years, with a random 275 cases and 275 matched controls used routinely for our genotyping studies, and other samples set aside for future independent studies. Samples used for the genotyping studies were all individuals, not families, with care taken not to include any related individuals in the casecontrol population. Case and control individuals were recruited from in and around the South Eastern Australia Region, with collections undertaken in the Genomics Research Centre Clinic at the Gold Coast, Queensland, Australia. To minimize potential bias from population stratification, the control group was matched for sex, age (+/- 5 years) and ethnicity. Migraine patients were clinically defined and suitably matched with non-migraine individuals who made up the control population. The subjects were diagnosed for migraine by a clinical neurologist using a detailed questionnaire in accordance with the International Headache Society criteria [2]. Questions used to define migraineurs included length and frequency of attack; pain location, type and intensity; associated symptoms such as nausea, vomiting, phonophobia, photophobia and other visual disturbances, and other neurological symptoms. All individuals were grouped together and phenotyped as being affected with typical migraine ( $\mathrm{MA}+\mathrm{MO}=$ Migraine $)$, as well as being diagnosed separately as $\mathrm{MA}$ or $\mathrm{MO}$ subgroups. The blood samples obtained from patients were collected through the Genomics Research Centre patient clinic and purified DNA from these samples was obtained using standard extraction methods. Around $90 \%$ of the examined DNA 
samples gave good genotyping results for the 4 selected genetic markers. We excluded the samples with unclear genotyping results. The study protocol was approved by Griffith University's Ethics Committee for Experimentation on Humans.

\section{Markers/genotyping}

The study investigated three different polymorphisms at the GABRE gene locus. The first marker was located in exon 3 of GABRE and named GABRE 3 for the study. GABRE 3 is a non synonymous SNP (ref database, rs 2050843) at position $102(\mathrm{G} \rightarrow \mathrm{T})$. PCR reactions $(10 \mu \mathrm{l}$ final volume) containing $2 \mathrm{mmol} / \mathrm{L} \mathrm{MgCl}_{2}, 0.8 \mathrm{~mol} / \mathrm{L} \mathrm{of}$ each primer, $200 \mathrm{~mol} / \mathrm{L}$ dNTPs, 1 unit of Taq polymerase and approximately 20 ng of genomic DNA were undertaken for genotyping purposes.

\section{Primers were:}

\section{Sense: 5'-TAGATGCTGAAACTGTGTGG-3'}

\section{Anti sense: 5'-AAATCCCTTTCTCCCTCCAG-3'}

Thermal cycling was performed with an initial denaturation of 60 seconds at $94^{\circ} \mathrm{C}$, followed by 35 cycles of $30 \mathrm{sec}$ at $94^{\circ} \mathrm{C}, 30 \mathrm{sec}$ at $58^{\circ} \mathrm{C}, 30 \mathrm{sec}$ at $72^{\circ} \mathrm{C}$, and a terminal extension of $10 \mathrm{~min}$ at $72^{\circ} \mathrm{C}$. PCR products were then digested with $\mathrm{Bgl} I I$ and analyzed by electrophoresis on 4\% agarose gels. Ethidium bromide stained gels were digitally imaged and manually scored for genotypes. The PCR products were $327 \mathrm{bp}$ in size. The GABRE $3 \mathrm{G}$ alleles did not digest with $B g l \mathrm{II}$, whereas $\mathrm{T}$ alleles digested to give $177 \mathrm{bp}$ and $150 \mathrm{bp}$ fragments.

The second marker was a synonymous SNP (ref SNP database, rs 2256882) at position $193(\mathrm{C} \rightarrow \mathrm{T})$ in exon 5, named GABRE 5. PCR reactions and thermal cycling conditions were the same as those cited above.

\section{Primers were:}

\section{Sense: 5'-GACTCTGGCCATTCATTGGT-3'}

\section{Anti sense: 5'-TGGCAGGAAAGGAAATGAGG-3'}

To detect this SNP, PCR products were digested with Hpa II and analyzed by electrophoresis on $4 \%$ agarose gels. Ethidium bromide stained gels were digitally imaged and manually scored for genotypes. The PCR products were $323 \mathrm{bp}$ in size. The GABRE $5 \mathrm{~T}$ alleles did not digest with Hрa II, whereas C alleles digested to give 180 bp and 143 bp fragments.

The last marker for GABRE gene was a new variation identified by sequencing exon 9 and identified at position 437
$(\mathrm{C} \rightarrow \mathrm{T})$, as a non synonymous SNP named GABRE 9. PCR reactions were again the same as those cited above.

Primers were:

Sense: 5'-ATGGTGAGAAGTTGGAGGAG-3'

Anti sense: 5'-AGAGGGGCAGCAAAGACAAA-3'

Thermal cycling was performed with an initial denaturation of 60 seconds at $94^{\circ} \mathrm{C}$, followed by 35 cycles of $30 \mathrm{sec}$ at $94^{\circ} \mathrm{C}, 30 \mathrm{sec}$ at $60^{\circ} \mathrm{C}, 30 \mathrm{sec}$ at $72^{\circ} \mathrm{C}$, and a terminal extension of $10 \mathrm{~min}$ at $72^{\circ} \mathrm{C}$. PCR products were then digested with Ava II and analyzed by electrophoresis on $2.5 \%$ agarose gels. Ethidium bromide stained gels were digitally imaged and manually scored for genotypes. The PCR products were $683 \mathrm{bp}$ in size. The GABRE $9 \mathrm{~T}$ alleles did not cut with Ava II and gave three fragments of $372 \mathrm{bp}$, $190 \mathrm{bp}$ and $121 \mathrm{bp}$, whereas C alleles gave $301 \mathrm{bp}, 190$ bp, $121 \mathrm{bp}$ and $71 \mathrm{bp}$ fragments.

The last marker studied was a synonymous SNP (ref SNP database, rs 3810651) at position $1432(\mathrm{~A} \rightarrow \mathrm{T})$ in exon 9 of GABRQ gene, named GABRQ. PCR amplicons of 300$500 \mathrm{nt}$ containing the 5 ' prime region and all 9 exons of the GABRQ gene, including intron/exon boundaries, were designed using the Oligo 4.0 software.

\section{Primers were:}

\section{Sense: 5'-TCTCTCCCCATCACCCCAGC-3'}

\section{Anti sense: 5'-TTCGACACGGTTGCGGATTT-3'}

PCR conditions were as follows; $1.5 \mathrm{mM}$ of $\mathrm{MgCl} 2,1 \times$ standard PCR buffer, $0.2 \mathrm{mM}$ of dNTPs, $0.5 \mu \mathrm{M}$ each of forward and reverse primers, 1 unit of Taq polymerase, 40 ng of genomic DNA, mixed to final volume of $25 \mu \mathrm{l}$ with sterile distilled water. The thermal cycle parameters included: 1 cycle at $95^{\circ} \mathrm{C}$ for $3 \mathrm{~min}$ for an initial denaturation, followed by 35 cycles of denaturation for $30 \mathrm{sec}$ at $94^{\circ} \mathrm{C}$, primer annealing for $30 \mathrm{sec}$ at TM, primer extension for $45 \mathrm{sec}$ at $72^{\circ} \mathrm{C}$ and a final extension for $10 \mathrm{~min}$ at $72^{\circ} \mathrm{C}$. Samples were then exosap digested (Amersham) and sequenced using the Big Dye Terminator Ready Reaction Kit (Applied Biosystem). Sequencing reactions were performed on a 9700 Thermal Cycler (Applied Biosystems) for 25 cycles of $95^{\circ} \mathrm{C}$ for $10 \mathrm{sec}$, TM for $5 \mathrm{sec}$ and $60^{\circ} \mathrm{C}$ for $2 \mathrm{~min}$. After the sequencing, each reaction was column purified (Amersham) to remove excess dye terminators. Sequencing of the products was performed on the ABI prism 3100 Genetic Analyser (Applied Biosystems). Polymorphisms were detected by multiple alignments of sequences using the program Autoassembler (Applied Biosystems). 


\section{Statistical analysis}

To detect association between each marker and migraine, we performed chi-square $\left(\chi^{2}\right)$ analysis to test for significant differences in allele and genotype frequencies in case versus control results [23]. $\chi^{2}$ provides the likelihood of a deviation in the distribution of the same attributes in different classes (e.g. allelic frequencies in controls versus affected subjects). If the probability ( $P$-value) of an equal distribution between the two groups is below a determined significance level $\alpha$ (in percent), the statistical output will show enough significance to assume LD and therefore association.

We performed $\chi^{2}$ analysis for $\mathrm{MA}, \mathrm{MO}$ and combined migraine groups versus control subjects for the GABRE 3, 5, 9 and GABRQ polymorphisms. We also tested for linkage disequilibrium between tested markers using Pearson's test to analyze dense genetic maps [24]. The R2 value 0.0 suggests independent assortment, whereas 1.0 means that all copies of the rarer allele occur exclusively with one of the possible alleles at the other marker [25].

In total, we compared each of the three markers in controls with three different case groups of the population (MA, MO, Migraine (MO+MA)). Results were also tested for Hardy-Weinberg Equilibrium (HWE) investigating genotype frequencies of the studied markers to detect a deviation from the normal genotype distribution in the population and odds ratios were calculated to characterize the distribution of distinct genotypes in different phenotypic subgroups of the population. A priori power analysis suggested that if any of the GABRE polymorphisms were to confer an 2-fold or greater difference in odds for migraine the total case and control groups used in this study were of sufficient size to have $>90 \%$ power to detect an allelic association and $>80 \%$ power to detect a genotypic association at the 0.05 level.

\section{Ethical approval}

This research was reviewed and approved by the Griffith University Human Research Ethics Committee (ethics protocol number MSC/05/05/HREC) and all subjects participating in the study gave informed consent.

\section{Results}

Three markers located within $15 \mathrm{~kb}$ of the coding region of the GABRE gene and a marker in the GABRQ gene were analyzed for association with migraine in a large population (275 migraineurs versus 275 healthy individuals) of Australia Caucasians. The distribution of GABRE 3, 5, 9 and GABRQ genotypes in the studied population did not deviate significantly from Hardy-Weinberg Equilibrium $(\mathrm{P}>0.05)$.
Table 1 represents the results of the allelic and genotypic frequency distribution of GABRE 3. There was no significant association between both allelic and genotype frequencies of GABRE 3 and migraine $\left(\chi^{2}=0.33, \mathrm{P}=0.56\right.$ and $\chi^{2}=0.73, \mathrm{P}=0.695$ respectively). Also, allelic frequencies in control groups $(\mathrm{pG}=0.762$ and $\mathrm{pT}=0.23$ ) are comparable to the frequencies reported previously in a Caucasian population $(\mathrm{pG}=0.692$ and $\mathrm{pT}=0.308)$ [26].

As shown in Table 1, the synonymous GABRE 5 marker distribution for allelic and genotype frequencies did not present significant association for migraine $\left(\chi^{2}=0.57, \mathrm{P}=\right.$ 0.45 and $\chi^{2}=0.95, \mathrm{P}=0.62$ respectively for allelic and genotype frequencies). Similarly to the previous marker, the allelic frequencies for GABRE 5 found in our population ( $\mathrm{pC}=0.88$ and $\mathrm{pT}=0.12)$, are similar to prior reports $(\mathrm{pC}=0.91$ and $\mathrm{pT}=0.08)$ in a European population [27].

The analysis of the non synonymous GABRE 9 marker also did not show any significant association with migraine $\left(\chi^{2}=0.76, \mathrm{P}=0.37\right.$ and $\chi^{2}=1.16, \mathrm{P}=0.56$ respectively for allelic and genotype frequencies).

Stratified analyses of migraine subtypes was also undertaken but did not indicate any association specifically attributed to the MA or MO subtype group for either allelic or genotypic frequencies for all of the three studied SNPs $(P>0.05)$. Similarly, when we analyzed by gender, no significant association was observed for the three GABRE genotype and allelic distributions ( $P>0.05)$ (cf. Table 1).

Statistical analysis of the GABRQ variant revealed no significant difference between genotyped migraineurs and the matched control group in relation to genotype frequencies $\left(\chi^{2}=0.57, \mathrm{P}=0.753\right)$ and allele frequencies $\left(\chi^{2}\right.$ $=0.19, \mathrm{P}=0.664$ ) (cf. Table 2). Furthermore, no significant difference was seen when the migraine population was subdivided into $\mathrm{MA}$ and $\mathrm{MO}$ compared to control group for both allelic and genotypic frequencies $(\mathrm{P}>$ $0.05)$, although the increased frequency of the TT genotype in MO (27\%) compared to MA (20\%) may warrant follow-up in a larger study group. The results were also not statistically different between the migraine and control groups regarding the gender $(\mathrm{P}>0.05)$. With regard to male allele frequencies, it was however interesting to note a higher frequency of the $\mathrm{T}$ allele in male $\mathrm{MO}$ migraineurs $(60 \%)$ compared to the male MA migraineurs $(41.2 \%)$ and the male control group (44.1\%).

Linkage disequilibrium analysis was also undertaken between the 3 GABRE and GABRQ markers. The analysis of LD between the GABRE markers revealed a moderate but significant linkage disequilibrium between GABRE 5 and GABRE $9\left(\mathrm{R}^{2}=0.38, \mathrm{P}=0.00001\right)$. However, this $\mathrm{LD}$ 
Table I: Distribution of the GABRE 3 mutation (Ser I02Ala), GABRE 5 mutation (Ala 193Ala), in migraineurs and controls of original sample (MO migraine without aura, MA migraine with aura).

\begin{tabular}{|c|c|c|c|c|c|c|}
\hline & $N$ & Alleles & & & Genotypes & \\
\hline Group & (alleles) & G & $T$ & GG & GT & $T T$ \\
\hline GABRE3 SNP & rs 2050843 & & & & & \\
\hline Migraine & 384 & 282 (73.4\%) & $102(26.6 \%)$ & 114 (59.4\%) & 54 (28.1\%) & $24(12.5 \%)$ \\
\hline Male & 112 & $84(75 \%)$ & $28(25 \%)$ & & & \\
\hline Female & 272 & 198 (73\%) & $74(27 \%)$ & 72 (53\%) & $54(39.7 \%)$ & $10(7.3 \%)$ \\
\hline MA & 254 & 194 (76.4\%) & $60(23.6 \%)$ & $77(60.6 \%)$ & $40(31.5 \%)$ & $10(7.9 \%)$ \\
\hline MO & 130 & $88(67.7 \%)$ & 42 (32.3\%) & $37(57 \%)$ & 14 (21.5\%) & $14(21.5 \%)$ \\
\hline Control & 374 & 285 (76.2\%) & $89(23.8 \%)$ & $119(63.6 \%)$ & 47 (25.2\%) & $21(11.2 \%)$ \\
\hline Male & 90 & $60(67 \%)$ & $30(33 \%)$ & & & \\
\hline Female & 284 & 225 (79.2\%) & 59 (20.8\%) & 89 (62.6\%) & 47 (33\%) & $6(4.4 \%)$ \\
\hline Total case vs control & & $X^{2}=0.33$ & $P=0.56$ & & $X^{2}=0.73$ & $P=0.695$ \\
\hline Subtype MA vs cont: & & $X^{2}=0.00$ & $P=0.99$ & & $X^{2}=2.08$ & $P=0.35$ \\
\hline \multirow[t]{2}{*}{ Subtype MO vs cont } & & $X^{2}=3.63$ & $P=0.06$ & & $X^{2}=4.3$ & $P=0.11$ \\
\hline & $\mathbf{N}$ & Alleles & & & Genotypes & \\
\hline Group & (alleles) & $T$ & $C$ & TT & TC & $C C$ \\
\hline GABRE5 SNP & rs 2256882 & & & & & \\
\hline Migraine & 332 & $34(10.3 \%)$ & 298 (89.7\%) & $6(3.4 \%)$ & $22(12.4 \%)$ & 149 (84.2\%) \\
\hline Male & 92 & $10(10.9 \%)$ & $82(89.1 \%)$ & & & \\
\hline Female & 262 & $24(9.2 \%)$ & $238(90.8 \%)$ & I (0.8\%) & $22(16.8 \%)$ & $108(82.4 \%)$ \\
\hline MA & 204 & $19(9.3 \%)$ & 185 (90.7\%) & $3(2.9 \%)$ & $13(12.8 \%)$ & $86(84.3 \%)$ \\
\hline MO & 152 & $16(10.5 \%)$ & $136(89.5 \%)$ & $3(3.9 \%)$ & $10(13.2 \%)$ & $63(82.9 \%)$ \\
\hline Control & 374 & 45 (12\%) & $329(88 \%)$ & $10(5.3 \%)$ & 25 (13.4\%) & $152(81.3 \%)$ \\
\hline Male & 104 & $12(11.5 \%)$ & $92(88.5 \%)$ & & & \\
\hline Female & 270 & $33(12.2 \%)$ & $237(87.8 \%)$ & $4(3 \%)$ & 25 (I8.5\%) & $106(78.5 \%)$ \\
\hline Total case vs control & & $X^{2}=0.57$ & $P=0.45$ & & $X^{2}=0.95$ & $P=0.62$ \\
\hline Subtype MA vs cont: & & $X^{2}=0.99$ & $P=0.32$ & & $X^{2}=0.94$ & $P=0.62$ \\
\hline \multirow[t]{2}{*}{ Subtype MO vs cont } & & $X^{2}=0.24$ & $P=0.62$ & & $X^{2}=0.23$ & $P=0.89$ \\
\hline & $\mathbf{N}$ & Alleles & & & Genotypes & \\
\hline Group & (alleles) & $T$ & $C$ & TT & TC & $C C$ \\
\hline \multicolumn{7}{|l|}{ GABRE9 SNP } \\
\hline Migraine & 316 & $20(6.3 \%)$ & 296 (93.7\%) & 7 (4.4\%) & $6(3.8 \%)$ & 145 (9|.8\%) \\
\hline Male & 88 & $6(6.8 \%)$ & $82(93.2 \%)$ & & & \\
\hline Female & 228 & $14(6.1 \%)$ & $214(93.9 \%)$ & $4(3.5 \%)$ & $6(5.3 \%)$ & $104(91.2 \%)$ \\
\hline MA & 198 & $9(4.5 \%)$ & $189(95.5 \%)$ & $3(3 \%)$ & $3(3 \%)$ & $93(94 \%)$ \\
\hline MO & 118 & $11(9.3 \%)$ & 107 (90.7\%) & $4(6.8 \%)$ & $3(5.1 \%)$ & $52(88.1 \%)$ \\
\hline Control & 280 & $23(8.2 \%)$ & 257 (91.8\%) & $7(5 \%)$ & $9(6.4 \%)$ & $124(88.6 \%)$ \\
\hline Male & 80 & $4(5 \%)$ & $76(95 \%)$ & & & \\
\hline Female & 200 & $19(9.5 \%)$ & $181(90.5 \%)$ & $5(5 \%)$ & $9(9 \%)$ & $86(86 \%)$ \\
\hline Total case vs control & & $X^{2}=0.79$ & $P=0.37$ & & $X^{2}=1.16$ & $P=0.56$ \\
\hline Subtype MA vs cont: & & $X^{2}=2.50$ & $P=0.11$ & & $X^{2}=2.06$ & $P=0.36$ \\
\hline Subtype MO vs cont & & $X^{2}=0.13$ & $P=0.72$ & & $X^{2}=0.36$ & $P=0.83$ \\
\hline
\end{tabular}

value decreased by more than $30 \%$ and become non significant $(P \geq 0.05)$ when measured between GABRE 3 and GABRE 5 on one hand, and GABRE 3 and GABRE 9 on the other hand (cf. Table 3). The analysis of LD between the 3 GABRE markers and GABRQ did not show any significant linkage disequilibrium $(\mathrm{P}>0.05)$ (cf. Table 3$)$.

\section{Discussion}

A substantial body of literature suggests that GABA may be involved in the neuropathophysiology of migraine yet there have been few studies investigating GABA receptor genes as potential candidate genes for migraine. $\gamma$-Amino butyric acid (GABA) is the major inhibitory neurotrans- mitter of the brain, occurring in $30-40 \%$ of all synapses in regions such as the cerebral cortex, hippocampus, thalamus, basal ganglia, cerebellum, hypothalamus and brainstem [28]. $\gamma$-Amino butyric acid type A (GABA A) receptors are the major sites of fast synaptic inhibition in the brain and are also the sites of action for many psychoactive drugs including the benzodiazepines and barbiturates [29]. In mammals, they are constructed as pentameric structures from multiple subunits selected predominantly from the following distinct classes: $\alpha$ (1$6), \beta(1-3), \gamma(1-3), \delta, \varepsilon, \theta$ and $\pi$, creating an incredible (165) potential for structural diversity. Studies have demonstrated that the subunit combination determined the 
Table 2: Distribution of the GABRQ gene exon 9 variation (P437I) in migraineurs and controls of original sample (MO migraine without aura, MA migraine with aura).

\begin{tabular}{|c|c|c|c|c|c|c|}
\hline & $\mathbf{N}$ & Alleles & & & Genotypes & \\
\hline & (alleles) & $A$ & $T$ & $A A$ & $A T$ & $T T$ \\
\hline GABRQ SNP & rs $381065 I$ & & & & & \\
\hline Migraine & 350 & $210(60 \%)$ & 140 (40\%) & 82 (40\%) & 74 (37\%) & $46(23 \%)$ \\
\hline Male & 54 & $28(51.8 \%)$ & $26(48.2 \%)$ & & & \\
\hline Female & 296 & $182(61.5 \%)$ & $114(38.5 \%)$ & $54(36 \%)$ & 74 (50\%) & 20 (14\%) \\
\hline MA & 208 & $131(63 \%)$ & $77(37 \%)$ & 54 (45\%) & 43 (35\%) & $24(20 \%)$ \\
\hline MO & 140 & 77 (55\%) & $63(55 \%)$ & 27 (34\%) & 31 (39\%) & $22(27 \%)$ \\
\hline Control & 367 & $226(61 \%)$ & $|4|$ (39\%) & 94 (44\%) & 72 (34\%) & 47 (22\%) \\
\hline Male & 59 & 33 (55.9\%) & $26(44.1 \%)$ & & & \\
\hline Female & 309 & $194(62.8 \%)$ & 115 (37.2\%) & 61 (40\%) & 73 (47\%) & 21 (13\%) \\
\hline Total case vs control & & $X^{2}=0.19$ & $P=0.664$ & & $X^{2}=0.57$ & $P=0.753$ \\
\hline Subtype MA vs cont: & & $X^{2}=0.11$ & $P=0.739$ & & $X^{2}=0.25$ & $P=0.88 I$ \\
\hline Subtype MO vs cont & & $X^{2}=1.82$ & $P=0.176$ & & $X^{2}=2.65$ & $P=0.265$ \\
\hline
\end{tabular}

affinity for GABA and the specific effects of allosteric modulators [14].

Recently, new members (epsilon and theta) of the GABA A receptor gene family have been discovered [30-32]. It is worth noting that alpha3-, theta- and epsilon-subunits are clustered on the X-chromosome [33] and that functional expression of recombinant receptors, as well as amino acid sequence identity analysis, have suggested that thetaand epsilon-subunits may substitute for beta- and gamma-subunits, respectively [33,34].

Functional expression of recombinant subunits has indicated that, in some brain areas (i.e. locus caeruleus, dorsal raphe, and hypothalamus) already demonstrated to be potentially involved in the migraine disorder, the theta subunit is co-expressed with epsilon and alpha3 subunits, suggesting that these subunits are associated in some native GABA A receptors [35].

In this study, we analyzed the distribution of genotype and allele frequencies of three SNPs located in the GABRE gene and one variant in the GABRQ gene in a large popu- lation of migraineurs and matched controls. Three of these markers are non synonymous SNPs (GABRE 3, GABRE 9 and a new variation in GABRQ) and induce changes of amino acids in the protein receptor (Ala102Ser and Pro437Leu, Ile478Phe respectively). The last SNP studied was synonymous (Ala193Ala), located in exon 5 of the GABRE gene (GABRE 5).

The study did not find any association between the three analysed SNPs in the GABRE gene and migraine. The GABRE gene contains 9 exons, which code for 4 different variants of GABRE [36]. The role of this splicing remains unclear at present. The first variant is a the full-length functional transcript and is highly expressed in heart and lung and also present in brain $[37,38]$. In variant 2 , exons 1-3 are spliced out, and in variant 3 the same splicing occurs in combination with a deletion of residues $127-$ 158 from the centre of exon 4 [36]. The mRNAs of variants 2 and 3 have been found in several peripheral tissues [37]. In variant 4 only exon 1 is deleted. Variants 2, 3 and 4 lack the signal peptide and also (for forms 2 and 3 ) lack a significant region of the extracellular $\mathrm{N}$-terminal domain,

Table 3: Pearson's correlation between the 3 GABRE and GABRQ genetic markers.

\begin{tabular}{ccccc}
\hline & GABRE 3 & GABRE 5 & GABRE 9 & GABRQ \\
\hline Pearson correlation (\%) & $\mathrm{I}$ & 0.133 & 0.074 & 0.002 \\
P value & & $0.019^{*}$ & 0.233 & 0.571 \\
Pearson correlation (\%) & 0.133 & 1 & 0.376 & 0.004 \\
P value & $0.019^{*}$ & & $0.00001^{* *}$ & 1 \\
Pearson correlation (\%) & 0.074 & 0.376 & 0.008 & 0.496 \\
P value & 0.233 & 0.0001 & 0.008 & 1 \\
Pearson correlation (\%) & 0.002 & 0.004 & 0.496 &
\end{tabular}

* Correlation is significant at the 0.05 level.

** Correlation is significant at the $0.00 \mathrm{I}$ level 
but the roles for these variants (form 2, 3 and 4) in combination with the full-length variant 1 remain unclear.

Our results also did not show any association between the tested GABRQ marker (rs 3810651) and migraine. No significant association was reported for both $\mathrm{MA}$ and $\mathrm{MO}$ populations for the studied single missense variation, A1432T. Of interest is the frequency distribution of the $\mathrm{T}$ allele in male $\mathrm{MO}(60 \%)$ patients versus male MA patients $(41.2 \%)$ and versus male controls $(44 \%)$. While this analysis did not reach statistical significance, due to small numbers in the male subgroup, it may warrant further investigation in a larger study group. The A1432T variation altered a conserved amino acid; the isoleucine amino acid is conserved in primate and mouse. The functional significance of the isoleucine residue in codon 478 is unknown but the high degree of conservation across several species argues strongly in favor of an important role of this amino acid in the function of GABRQ protein. The hypothesis that the isoleucine residue in codon 478 may constitute an important point for GABRQ function, which would be perturbed (pathogenic) by the phenylalanine substitution, should be considered.

Previous linkage studies in our research group have reported mapping of a migraine gene to the $\mathrm{X}$ chromosome in three large Australian pedigrees [20,39]. Although results from haplotype and linkage analyses (employing 28 markers spanning the entire X chromosome) localized the disease locus in the Xq 24-28 region, these findings may be specific to the studied population, which may not be representative of the general population [20].

The GABA neurotransmitter has been previously implicated in the pathophysiology of migraine, but there have been only recent studies in migraine genetics. Russo et al. reported significant linkage, in five Italian families suffering from a migraine subtype with the 15q11-q13 chromosomal region, a region containing clusters of GABA A receptor subunit (beta 3, alpha 5 and gamma 3) genes [40]. More studies need to be undertaken and in particular, on other genetic markers in the other GABA receptors genes present in the Xq28 gene cluster. The GABA A receptor subunit alpha 3 (GABRA3) gene is also located in this region. A dinucleotide cytosine-adenosine repeat polymorphism with 6 alleles representing 11 to 16 repeats has been described by Hicks (2000) in the GABRA3 gene [41]. This polymorphism has been associated with Multiple Sclerosis [42], but also with Bipolar Disorder [43,44]. Both of these neurological disorders shared a comorbidity with migraine [45]. A GABRA3 microsatellite has been also studied in another psychiatric disorder population (suicide attempts) but no significant association has been reported for this genetic marker [46].
GABA levels in the cerebro-spinal fluid of patients during a migraine attack have been reported to be higher compared to the levels measured during a headache free period in the same individuals [47]. Kowa et al. (1992), have also observed higher GABA levels in blood platelets of patients suffering from tension headache [48]. Furthermore, the GABAergic migraine prophylactic drugs may restore a normal cortical inhibitory potential by elevating cortical threshold for spreading depression propagation in patients with migraines [49]. GABA neurotransmitter plays a key part in cerebral physiology, and is able to inhibit a number of neurohormones including serotonin, catecholamines and glutamate. Like other ligand gated ion channels, such as the GABA A receptor, the ionotropic glutamate receptor subunits possess four subunits. The ionotropic glutamate receptor, AMPA-selective glutamate receptor 3, has been located to the Xq 24-28 region, mapped migraine susceptibility [50].

\section{Conclusion}

Previous studies in our laboratory have reported significant evidence for the location of a migraine susceptibility locus on chromosome Xq [39] and more specifically to the Xq 24-28 region [20]. Previous candidate genes 5$\mathrm{HT}_{2 \mathrm{C}}$ receptor gene, residing in this region have not revealed genetic differences between migraineurs compared to controls [51-53]. Also, lack of association of Monoamine Oxidase genes located on chromosome $\mathrm{X}$, with migraine susceptibility has been reported in several studies [54-56]. Chromosome X studies and migraine susceptibility have been investigated for the last decade. The prevalence of migraine in children before puberty has been reported to be quite similar in boys and girls (4\%) [57] but migraine occurs more frequently in adult women $(18 \%)$ than in men (6\%) [58]. GABAergic neurons are strongly modulated by ovarian hormones with studies showing an effect of estrogen and progesterone and its metabolites on GABA receptors [59-61], as well as cortical GABA levels [62]. Although this study has not implicated tested markers in the GABRE gene, further investigation of other GABA related genes, particularly in the cluster of GABA A receptor subunit genes residing at Xq 24-28 region, is required to define their potential role in migraine.

\section{Competing interests}

The authors declare that they have no competing interests.

\section{Authors' contributions}

FF and TE were responsible for undertaking all the experiments and the analysis of data was undertaken collaboratively by all authors. LG coordinated the study and revised the manuscript. All authors read and approved the final manuscript. 


\section{Acknowledgements}

This work was supported by funding from an ARC Linkage and an NHMRC Grant from Australia

\section{References}

I. Lance JW: Current concepts of migraine pathogenesis. Neurology 1993, 43(6 Suppl 3):SII-I5.

2. HCCIHS: Headache Classification Committee for the International Headache Society. Classification and diagnostic criteria for headache disorders, cranial neuralgias and facial pain 2nd edition. Cephalgia 2004, 24(SuppI I): I-60.

3. Ferrari MD, Odink J, Tapparelli C, Van Kempen GM, Pennings EJ, Bruyn GW: Serotonin metabolism in migraine. Neurology 1989, 39(9): I239-1242.

4. Goadsby PJ, Gundlach AL: Localization of $\mathbf{3 H}$-dihydroergotamine-binding sites in the cat central nervous system: relevance to migraine. Ann Neurol I991, 29(I):91-94.

5. Ramadan NM: The link between glutamate and migraine. CNS Spectr 2003, 8(6):446-449.

6. Pietrobon D, Striessnig J: Neurobiology of migraine. Nat Rev Neurosci 2003, 4(5):386-398.

7. Bolay H, Reuter U, Dunn AK, Huang Z, Boas DA, Moskowitz MA: Intrinsic brain activity triggers trigeminal meningeal afferents in a migraine model. Nat Med 2002, 8(2): | 36-| 42.

8. Calabresi P, Galletti F, Rossi C, Sarchielli P, Cupini LM: Antiepileptic drugs in migraine: from clinical aspects to cellular mechanisms. Trends Pharmacol Sci 2007.

9. Silberstein SD: Chronic migraine: diagnosis and management strategy. Rev Neurol Dis 2004, I(3): I55-I60.

10. Hering-Hanit R: Baclofen for prevention of migraine. Cephalalgia 1999, I9(6):589-591.

II. Hering R, Kuritzky A: Sodium valproate in the prophylactic treatment of migraine: a double-blind study versus placebo. Cephalalgia 1992, I2(2):81-84.

12. Klapper J: Divalproex sodium in migraine prophylaxis: a dosecontrolled study. Cephalalgia 1997, I 7(2): I03-108.

13. Cromer BA, Morton C], Parker MW: Anxiety over GABA(A) receptor structure relieved by $\mathrm{AChBP}$. Trends Biochem Sci 2002, 27(6):280-287.

14. Barnard EA, Skolnick P, Olsen RW, Mohler H, Sieghart W, Biggio G, Braestrup C, Bateson AN, Langer SZ: International Union of Pharmacology. XV. Subtypes of gamma-aminobutyric acidA receptors: classification on the basis of subunit structure and receptor function. Pharmacol Rev 1998, 50(2):29|-3।3.

15. Dalsgaard-Nielsen T: [Migraine - a misunderstood disease]. Sygeplejersken 1972, 72(10):7-9.

16. Russell MB, Ulrich V, Gervil M, Olesen J: Migraine without aura and migraine with aura are distinct disorders. A populationbased twin survey. Headache 2002, 42(5):332-336.

17. Russell MB, Rasmussen BK, Fenger K, Olesen J: Migraine without aura and migraine with aura are distinct clinical entities: a study of four hundred and eighty-four male and female migraineurs from the general population. Cephalalgia 1996, I 6(4):239-245.

18. Nyholt DR, Gillespie NG, Heath AC, Merikangas KR, Duffy DL, Martin NG: Latent class and genetic analysis does not support migraine with aura and migraine without aura as separate entities. Genet Epidemiol 2004, 26(3):23 I-244.

19. Ligthart L, Boomsma DI, Martin NG, Stubbe JH, Nyholt DR: Migraine with aura and migraine without aura are not distinct entities: further evidence from a large Dutch population study. Twin Res Hum Genet 2006, 9(I):54-63.

20. Nyholt DR, Curtain RP, Griffiths LR: Familial typical migraine: significant linkage and localization of a gene to $X q$ 24-28. Hum Genet 2000, I07(I): I8-23.

21. Nyholt DR, Lea RA, Goadsby PJ, Brimage PJ, Griffiths LR: Familial typical migraine: linkage to chromosome $19 \mathrm{p} / 3$ and evidence for genetic heterogeneity. Neurology 1998, 50(5): | 428-|432.

22. Sinkkonen ST, Hanna MC, Kirkness EF, Korpi ER: GABA(A) receptor epsilon and theta subunits display unusual structural variation between species and are enriched in the rat locus caeruleus. I Neurosci 2000, 20( I 0):3588-3595.

23. Nahmias J, Burley MW, Povey S, Porter C, Craig I, Wolfe J: A I 9 bp deletion polymorphism adjacent to a dinucleotide repeat polymorphism at the human dopamine beta-hydroxylase locus. Hum Mol Genet 1992, I(4):286.

24. Purcell S, Cherny SS, Sham PC: Genetic Power Calculator: design of linkage and association genetic mapping studies of complex traits. Bioinformatics 2003, I9(I): |49-I50.

25. Pittman AM, Myers AJ, Abou-Sleiman P, Fung HC, Kaleem M, Marlowe L, Duckworth J, Leung D, Williams D, Kilford L, et al.: Linkage disequilibrium fine mapping and haplotype association analysis of the tau gene in progressive supranuclear palsy and corticobasal degeneration. J Med Genet 2005, 42(I I):837-846.

26. National Centre for Biotechnology Information [http:// www.ncbi.nlm.nih.gov/]

27. National Center for Biotechnology Information [http:// www.ncbi.nlm.nih.gov/]

28. McCormick DA: GABA as an inhibitory neurotransmitter in human cerebral cortex. J Neurophysiol 1989, 62(5): I018-1027.

29. Olsen RW, Tobin AJ: Molecular biology of GABAA receptors. Faseb J 1990, 4(5): |469-| 480.

30. Whiting PJ, McAllister G, Vassilatis D, Bonnert TP, Heavens RP, Smith DW, Hewson L, O'Donnell R, Rigby MR, Sirinathsinghii DJ, et al.: Neuronally restricted RNA splicing regulates the expression of a novel GABAA receptor subunit conferring atypical functional properties [corrected; erratum to be published]. ] Neurosci 1997, I7(13):5027-5037.

31. Garret M, Bascles L, Boue-Grabot E, Sartor P, Charron G, Bloch B, Margolskee RF: An mRNA encoding a putative GABA-gated chloride channel is expressed in the human cardiac conduction system. J Neurochem 1997, 68(4): I 382-1389.

32. Davies PA, Hanna MC, Hales TG, Kirkness EF: Insensitivity to anaesthetic agents conferred by a class of GABA(A) receptor subunit. Nature 1997, 385(66 19):820-823.

33. Bailey ME, Matthews DA, Riley BP, Albrecht BE, Kostrzewa M, Hicks AA, Harris R, Muller U, Darlison MG, Johnson KJ: Genomic mapping and evolution of human GABA(A) receptor subunit gene clusters. Mamm Genome 1999, I0(8):839-843.

34. Xue $\mathrm{H}$ : Identification of major phylogenetic branches of inhibitory ligand-gated channel receptors. I Mol Evol 1998, 47(3):323-333.

35. Moragues N, Ciofi P, Lafon P, Tramu G, Garret M: GABAA receptor epsilon subunit expression in identified peptidergic neurons of the rat hypothalamus. Brain Res 2003, 967(I2):285-289.

36. Simon J, Wakimoto $H$, Fujita N, Lalande M, Barnard EA: Analysis of the set of $\mathrm{GABA}(\mathrm{A})$ receptor genes in the human genome. J Biol Chem 2004, 279(40):4I422-4I435.

37. Wilke K, Gaul R, Klauck SM, Poustka A: A gene in human chromosome band Xq28 (GABRE) defines a putative new subunit class of the GABAA neurotransmitter receptor. Genomics 1997, 45(I): I- 10 .

38. Garrett KM, Barron KW, Briscoe RJ, Heesch CM: Neurosteroid modulation of $[3 \mathrm{H}]$ flunitrazepam binding in the medulla: an autoradiographic study. Brain Res 1997, 768(I-2):30I-309.

39. Nyholt DR, Dawkins JL, Brimage PJ, Goadsby PJ, Nicholson GA, Griffiths LR: Evidence for an X-linked genetic component in familial typical migraine. Hum Mol Genet 1998, 7(3):459-463.

40. Russo L, Mariotti P, Sangiorgi E, Giordano T, Ricci I, Lupi F, Chiera R, Guzzetta F, Neri G, Gurrieri F: A new susceptibility locus for migraine with aura in the $|5 q| l-q \mid 3$ genomic region containing three GABA-A receptor genes. Am J Hum Genet 2005, 76(2):327-333.

4I. Hicks AA, Johnson KJ, Barnard EA, Darlison MG: Dinucleotide repeat polymorphism in the human $X$-linked GABAA receptor alpha 3-subunit gene. Nucleic Acids Res 1991, I9( I4):4016.

42. Gade-Andavolu R, MacMurray JP, Blake H, Muhleman D, Tourtellotte W, Comings DE: Association between the gamma-aminobutyric acid A3 receptor gene and multiple sclerosis. Arch Neurol 1998, 55(4):513-516.

43. Massat I, Souery D, Del-Favero J, Oruc L, Noethen MM, Blackwood D, Thomson M, Muir W, Papadimitriou GN, Dikeos DG, et al.: Excess of allelel for alpha3 subunit GABA receptor gene (GABRA3) in bipolar patients: a multicentric association study. Mol Psychiatry 2002, 7(2):201-207.

44. Duffy A, Turecki G, Grof P, Cavazzoni P, Grof E, Joober R, Ahrens B, Berghofer A, Muller-Oerlinghausen B, Dvorakova M, et al.: Association and linkage studies of candidate genes involved in 
GABAergic neurotransmission in lithium-responsive bipolar disorder. J Psychiatry Neurosci 2000, 25(4):353-358.

45. Nuyen J, Schellevis FG, Satariano WA, Spreeuwenberg PM, Birkner MD, Bos GA van den, Groenewegen PP: Comorbidity was associated with neurologic and psychiatric diseases: a general practice-based controlled study. J Clin Epidemiol 2006, 59(I 2): | 274-I 284.

46. Baca-Garcia E, Vaquero C, Diaz-Sastre C, Jimenez-Trevino L, SaizRuiz J, Fernandez-Piqueras J, de Leon J: Lack of association between polymorphic variations in the alpha 3 subunit GABA receptor gene (GABRA3) and suicide attempts. Prog Neuropsychopharmacol Biol Psychiatry 2004, 28(2):409-4I 2.

47. Welch KM, Chabi E, Bartosh K, Achar VS, Meyer JS: Cerebrospinal fluid gamma aminobutyric acid levels in migraine. $\mathrm{Br}$ Med J 1975, 3(5982):516-517.

48. Kowa H, Shimomura T, Takahashi K: Platelet gamma-aminobutyric acid levels in migraine and tension-type headache. Headache 1992, 32(5):229-232.

49. Palmer JE, Chronicle EP, Rolan P, Mulleners WM: Cortical hyperexcitability is cortical under-inhibition: evidence from a novel functional test of migraine patients. Cephalalgia 2000, 20(6):525-532.

50. Keinanen K, Wisden W, Sommer B, Werner P, Herb A, Verdoorn TA, Sakmann B, Seeburg PH: A family of AMPA-selective glutamate receptors. Science 1990, 249(4968):556-560.

51. Johnson MP, Lea RA, Curtain RP, MacMillan JC, Griffiths LR: An investigation of the 5-HT2C receptor gene as a migraine candidate gene. Am J Med Genet 2003, I I 7B(I):86-89.

52. Burnet PW, Harrison PJ, Goodwin GM, Battersby S, Ogilvie AD, Olesen J, Russell MB: Allelic variation in the serotonin 5-HT2C receptor gene and migraine. Neuroreport 1997 8(I 2):265I-2653.

53. Racchi M, Leone M, Porrello E, Rigamonti A, Govoni S, Sironi M, Montomoli $\mathrm{C}$, Bussone G: Familial migraine with aura: association study with 5-HTIB/ID, 5-HT2C, and hSERT polymorphisms. Headache 2004, 44(4):3 II-3I7.

54. Marziniak M, Mossner R, Benninghoff J, Syagailo YV, Lesch KP, Sommer C: Association analysis of the functional monoamine oxidase A gene promotor polymorphism in migraine. J Neural Transm 2004, III(5):603-609.

55. Johnson MP, Griffiths LR: A genetic analysis of serotonergic biosynthetic and metabolic enzymes in migraine using a DNA pooling approach. J Hum Genet 2005, 50(12):607-6I0.

56. Cevoli S, Mochi M, Scapoli C, Marzocchi N, Pierangeli G, Pini LA, Cortelli P, Montagna P: A genetic association study of dopamine metabolism-related genes and chronic headache with drug abuse. Eur J Neurol 2006, 13(9): 1009-1013.

57. Goldstein M, Chen TC: The epidemiology of disabling headache. Adv Neurol 1982, 33:377-390.

58. Lipton RB, Stewart WF: Prevalence and impact of migraine. Neurol Clin 1997, I 5(I): I-13.

59. Shughrue PJ, Merchenthaler I: Estrogen is more than just a "sex hormone": novel sites for estrogen action in the hippocampus and cerebral cortex. Front Neuroendocrinol 2000, 2I(I):95-101.

60. Kelly MJ, Loose MD, Ronnekleiv OK: Estrogen suppresses muopioid- and GABAB-mediated hyperpolarization of hypothalamic arcuate neurons. J Neurosci 1992, I 2(7):2745-2750.

61. Twyman RE, Macdonald RL: Neurosteroid regulation of GABAA receptor single-channel kinetic properties of mouse spinal cord neurons in culture. J Physiol 1992, 456:2 I5-245.

62. Epperson CN, Haga K, Mason GF, Sellers E, Gueorguieva R, Zhang W, Weiss E, Rothman DL, Krystal JH: Cortical gamma-aminobutyric acid levels across the menstrual cycle in healthy women and those with premenstrual dysphoric disorder: a proton magnetic resonance spectroscopy study. Arch Gen Psychiatry 2002, 59(9):85I-858.

\section{Pre-publication history}

The pre-publication history for this paper can be accessed here:

http://www.biomedcentral.com/1471-2350/9/109/pre pub
Publish with Biomed Central and every scientist can read your work free of charge

"BioMed Central will be the most significant development for disseminating the results of biomedical research in our lifetime. "

Sir Paul Nurse, Cancer Research UK

Your research papers will be:

- available free of charge to the entire biomedical community

- peer reviewed and published immediately upon acceptance

- cited in PubMed and archived on PubMed Central

- yours - you keep the copyright

Submit your manuscript here:

http://www.biomedcentral.com/info/publishing_adv.asp
BioMedcentral 